\title{
The efficacy and safety of Tipapkinogen Sovacivec therapeutic HPV vaccine in cervical intraepithelial neoplasia grades 2 and 3: Randomized controlled phase II trial with 2.5 years of follow-up
}

\author{
Diane M. Harper ${ }^{\mathrm{a}, *, 1}$, Pekka Nieminen ${ }^{\mathrm{b}}$, Gilbert Donders ${ }^{\mathrm{c}}$, Mark H. Einstein ${ }^{\mathrm{d}, 2}$, Francisco Garcia ${ }^{\mathrm{e}, 3}$, \\ Warner K. Huh ${ }^{\mathrm{f}}$, Mark H. Stoler ${ }^{\mathrm{g}}$, Katerina Glavini ${ }^{\mathrm{h}}$, Gemma Attley ${ }^{\mathrm{i}}$, Jean-Marc Limacher ${ }^{\mathrm{j}, 4}$, \\ Berangere Bastien ${ }^{\mathrm{k}}$, Elizabeth Calleja ${ }^{\mathrm{i}, 5}$
}

a Department of Family and Community Medicine, Obstetrics and Gynecology, University of Missouri Kansas City, 7900 Lee's Summit Road, Kansas City, MO 64139, USA

${ }^{\mathrm{b}}$ Department of Obstetrics and Gynaecology, Helsinki University Hospital and Helsinki University, Box 615, 00029 HUS, Helsinki, Finland

' Department of Obstetrics and Gynaecology, University Hospital Antwerp, Wilrijksesteenweg 10, 2000 Antwerp-Ekeren, Belgium

d Department of Obstetrics and Gynecology, Albert Einstein Cancer Center and Montefiore Medical Center, 111 East 210th Street, Bronx, NY 10467, USA

e Center of Excellence in Women's Health at the University of Arizona, 1501 N Campbell Ave, Tucson, AZ 85714, USA

${ }^{\mathrm{f}}$ Department of Obstetrics and Gynecology, University of Alabama, 1700 6th Avenue South, WIC Room 10250, Birmingham, AL 35233, USA

g Surgical Pathology, P.O. Box 800214, Department of Pathology, University of Virginia Health System, University of Virginia, Charlottesville, VA, USA

${ }^{\mathrm{h}}$ Roche Pharmaceutical Research E' Early Development, Roche Innovation Center Basel, F. Hoffmann-La Roche Ltd. Building 93, Room 7.38.01, Grenzacherstrasse 124, Basel 4070, Switzerland

${ }^{i}$ Roche Pharmaceutical Research E' Early Development, Roche Innovation Center New York, 430 E. 29th Street New York City, New York 10016, USA

j Department of Medical Affairs, Transgene SA, 400 Bb Gonthier d'Andernach Parc d'innovation, CS80166, 67405 Illkirch-Graffenstaden Cedex, France

${ }^{\mathrm{k}}$ Department of Biostatistics, Transgene S.A., Boulevard Gonthier d'Andernach Parc d'innovation, CS80166, 67405 Illkirch-Graffenstaden Cedex, France

\section{H I G H L I G H T S}

- Tipapkinogen sovacivec completely resolves CIN 3 lesions significantly more frequently than placebo.

- Tipapkinogen sovacivec completely clears HPV16 viral DNA associated with CIN 2/3 significantly more often than placebo.

- Tipapkinogen sovacivec has significantly greater complete resolution rates of CIN $2 / 3$ regardless of HR HPV type.

- Tipapkinogen sovacivec offers 36\% complete resolution or partial response of CIN2/3 associated with all HR HPV types.

\section{A R T I C L E I N F O}

\section{Article history:}

Received 14 January 2019

Received in revised form 19 March 2019

Accepted 21 March 2019

Available online $\mathrm{xxxx}$

\section{Keywords:}

CIN 2/3

Immunotherapy

HPV

Cervical cancer

Therapeutic vaccine

Women

\section{A B S T R A C T}

Background. While prophylactic human papillomavirus (HPV) vaccination exists, women are still developing cervical intraepithelial neoplasia (CIN) grade 2 or 3 for which an immunotherapeutic, non-surgical, approach may be effective. The primary aim was to assess the efficacy of tipapkinogen sovacivec (TS) vaccine in achieving histologic resolution of CIN2/3 associated with high risk (HR) HPV types.

Methods. Women 18 years and older who had confirmed CIN2/3 were enrolled in a randomized, double blind, placebo-controlled phase II trial and assigned to drug in a 2:1 ratio (vaccine:placebo). The primary endpoint occurred at month 6 when the excisional therapy was performed; cytology and HR HPV typing were performed at months 3, 6 and every six months through month 30 . The safety population included all patients who received at least one dose of study drug.

Results. Of the 129 women randomized to vaccine and 63 to placebo, complete resolution was significantly higher in the vaccine group than placebo for CIN 2/3 regardless of the 13 HR HPV types assayed ( $24 \%$ vs. $10 \%, p$ $<0.05$ ); as well as for only CIN 3 also regardless of HR HPV type ( $21 \%$ vs. $0 \%, p<0.01$ ). Irrespective of baseline HPV infection, viral DNA clearance was higher in the vaccine group compared to placebo $(\mathrm{p}<0.01)$. The vaccine

\footnotetext{
* Corresponding author at: University of Michigan, 1018 Fuller Street, Ann Arbor, MI 48102, United States of America.

E-mail addresses: harperdi@med.umich.edu (D.M. Harper), pekka.nieminen@hus.fi (P. Nieminen), Gilbert.Donders@uza.be (G. Donders), me399@njms.rutgers.edu (M.H. Einstein),

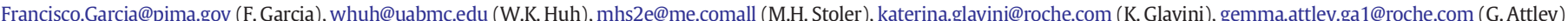
, jean-marc.limacher@ch-colmar.fr (J.-M. Limacher), bastien@transgene.fr (B. Bastien), elizabethcalleja@netscape.net (E.Calleja).

1 Present address: Department of Family Medicine, Obstetrics and Gynecology, University of Michigan, 1018 Fuller Street, Ann Arbor MI 48105 USA.

2 Present address: Department of Obstetrics and Gynecology. Rutgers New Jersey Medical School, Newark, NJ, USA.

${ }^{3}$ Present address: Director and Chief Medical Officer of the Pima County Department of Health, 130 W. Congress Street, 10th Floor Suite, Tucson AZ 85701, USA

4 Present address: Louis Pasteur Hospital, Department of Oncology and Hematology, 39 Avenue de la Liberte 68,000 Colmar Alsace France.

5 Present address: Taiho Oncology, Inc. 101 Carnegie Center, Suite 101. Princeton, NJ 08540. USA.
} 
was well tolerated with the most common adverse events being injection site reactions.

Conclusions. The TS vaccine provides histologic clearance of CIN 2/3 irrespective of HR HPV type in one third of subjects and is generally safe through 30 months.

(C) 2019 The Authors. Published by Elsevier Inc. This is an open access article under the CC BY-NC-ND license (http:// creativecommons.org/licenses/by-nc-nd/4.0/).

\section{Introduction}

Immunotherapeutic advances against human papillomavirus (HPV) are the next frontier in treating at least six different cancers or cancer precursors of the cervix, anus, vulva, vagina, penis, and oropharynx [6]. Of these, cervical cancer comprises over $80 \%$ of the HPV associated cancer global burden [3,5], and, despite the high surgical cure rate, is the focus of therapeutic vaccine development. While prophylactic HPV vaccines prevent infections from half of the HR HPV types associated with cancer, there is a clinical need for non-surgical, non-ablative therapeutics to control HPV diseases. In addition, surgical and ablative therapies, while effective, are associated with reproductive morbidities [17-19]; and recurrence can occur, especially with positive surgical margins, likely because of persistent viral infection [2,22]. Furthermore, current screening strategies have no therapeutic option for women with persistent HPV infections whose likelihood of cancer progression is unknown [24].

The modified vaccinia virus Ankara (MVA) is a highly attenuated replication-deficient strain of vaccinia virus used widely as a genedelivery system of vaccines. TS has inserted genes that code for three proteins: human cytokine IL-2, and modified forms of HPV 16 E6 and E7 proteins that have been rendered non oncogenic. MVA by itself contributes to the immune reaction by the induction of an Interferon-alpha response [11]. Upon sub-cutaneous injection, TS infects the surrounding cells. The expressed HPV16 E6 and E7 proteins are then processed and presented by dendritic cells which are co-activated by the viral infection. These dendritic cells migrate to the draining lymph-node and present E6 and E7 peptides to the naive T-cells present in the lymph-node, which should allow development of a targeted cell mediated immune response.

Preclinical and early clinical studies suggest that TS can cause CIN2/3 resolution by induction of a cell mediated immune response [4]. The primary aim of this study was to assess the efficacy of TS compared to placebo to achieve complete histologic resolution (no CIN) at month 6 in subjects with CIN2/3 associated with HPV 16 monoinfection. This analysis is extended to include complete resolution and partial lesion response associated with other HR HPV infections. The secondary aims are to assess viral DNA clearance over 2.5 years after definitive excision at month 6 and safety assessment.

\section{Methods}

\subsection{Study design and participants}

This study was a multicenter, prospective, randomized, doubleblind, 2-arm parallel group, placebo-controlled, phase IIb trial conducted in the United States, Spain, Belgium, France, and Finland, among 66 study locations. This trial was registered at Clinicaltrials.gov identifier NCT01022346; EudraCT 2008-006946-24. The protocol was approved by the institutional review board or ethics committee at each participating institution, and all patients gave written informed consent. Women were recruited based on known colposcopic biopsy results at their home institutions.

Women aged 18 years and older were invited to enroll if they had a histologically confirmed central pathology review (CPR) panel reconfirmation of a first diagnosis of CIN2/3 associated with single or multiple HR HPV infections. To be included in the study, women had to have residual disease present after biopsy, involving at least one, but no more than two quadrants, and did not have colposcopic characteristics that would be concerning for invasive disease. These restrictions were enforced to rule out potential occult microinvasive cancers [25].

Women who had received a prophylactic HPV vaccine were excluded. Women who had prior excisional or ablative therapy for any CIN, vulvar intraepithelial neoplasia (VIN) or vaginal intraepithelial neoplasia (VaIN), or any atypical endometrial or glandular cells or carcinoma were excluded. In addition, women were excluded if they were pregnant or breast-feeding, co-infected with hepatitis B, hepatitis C, cytomegalovirus, Epstein Barr virus or HIV, or had other immune deficient states.

\subsection{Study randomization, dosing and blinding}

Study subjects were randomized in a 2:1 ratio (TS vaccine:placebo) and stratified based on the HR HPV type: HPV 16 monoinfection (stratum 1) vs. other HR HPV single or multiple infections (stratum 2), which are defined as the alpha 5, 6, 7 and 9 clades (HPV 51; and HPV 56; and HPV 18, 39, 45, 59, 68; and HPV 16, 31,33, 35, 52, 58, respectively as detailed in Table 1). Placebo doses were prepared and labelled in identical syringes by a study pharmacist at each institution.

The study CPR was blinded to the randomization process, as were the laboratory personnel performing HPV typing and clinical personnel delivering the injections.

\subsection{Procedures}

Study subjects with CIN2/3 were recruited from August 2009September 2011. Those meeting study eligibility were assigned to drug or placebo which was injected subcutaneously in the thigh, on days 1,8 , and 15 .

Subjects returned at month 3 and month 6 for cytology and HR HPV testing. Colposcopy was performed at month 3 where biopsies were taken only at the investigator's discretion. At month 6 , subjects underwent definitive treatment (loop electrosurgical excision procedure (LEEP/LLETZ) or conization) as well as HR HPV typing. Subjects continued follow-up every six months until month 30 with repeat cytology, HR HPV testing, adverse event assessments and colposcopy and biopsy, if clinically needed.

Subjects recorded injection site reactions in their diary every day for seven days following each injection, to assess tenderness, pruritus, erythema, induration and pain. Adverse events were recorded using the Medical Dictionary of Regulatory Activities (MedDRA) version 16.1 throughout the trial. Serious adverse events were recorded and assessed by both the site investigators and the blinded medical monitor. These data, including hematology and blood chemistries, were reviewed for safety in real time.

\subsection{Outcomes}

The primary efficacy endpoint was the individual histological resolution at six months after the first injection in the HPV16 monoinfected modified intent to treat (mITT) population defined as subjects receiving at least one dose of study drug and who were confirmed to have CIN2 or 3 at baseline by the CPR panel. Other exploratory efficacy endpoints included histological complete resolution or partial response (CIN1) six months after the first injection. These exploratory analyses included age, CIN category, HPV type infection, and number of quadrants of lesion 
Table 1

Demographics of study patients at baseline by randomization group: Intent to Treat (ITT) population for safety analysis.

\begin{tabular}{|c|c|c|}
\hline & \multirow{2}{*}{$\begin{array}{l}\text { Tipapkinogen } \\
\text { sovacivec } \\
\text { vaccine } \\
N=136\end{array}$} & \multirow{2}{*}{$\begin{array}{l}\text { Placebo } \\
N=70\end{array}$} \\
\hline & & \\
\hline Age, yrs. mean (SD) & $30.1(7.8)$ & $\begin{array}{l}29.8 \\
(7.6)\end{array}$ \\
\hline Range (Min-max), yrs & $18-60$ & $19-50$ \\
\hline$\leq 30$ years, $\mathrm{n}(\%)$ & $84(62)$ & $44(63)$ \\
\hline$>30$ years, $\mathrm{n}(\%)$ & $52(38)$ & $26(37)$ \\
\hline \multicolumn{3}{|l|}{ Ethnicity/Race, n (\%) } \\
\hline Hispanic & $32(24)$ & $9(13)$ \\
\hline Not Hispanic, Black & $10(7)$ & $8(11)$ \\
\hline Not Hispanic, White & $89(65)$ & $51(73)$ \\
\hline Not Hispanic, Other & $5(4)$ & $2(3)$ \\
\hline \multicolumn{3}{|l|}{ Global, n (\%) } \\
\hline US & $84(62)$ & $40(57)$ \\
\hline Western Europe & $52(38)$ & $30(43)$ \\
\hline \multicolumn{3}{|l|}{$\begin{array}{l}\text { Central panel review histologic diagnoses, } \mathrm{n} \\
(\%)\end{array}$} \\
\hline$<\mathrm{CIN} 2^{\mathrm{a}}$ & $5(4)$ & $6(9)$ \\
\hline CIN 2 & $53(39)$ & $30(43)$ \\
\hline CIN 3 & $76(56)$ & $33(47)$ \\
\hline Adenocarcinoma-in-situ ${ }^{a}$ & $1(1)$ & $1(1)$ \\
\hline Body mass index (BMI) $\left(\mathrm{kg} / \mathrm{m}^{2}\right)$ mean $(\mathrm{SD})$ & $25.2(5.9)$ & $\begin{array}{l}25.2 \\
(6.8)\end{array}$ \\
\hline \multicolumn{3}{|l|}{ History of small pox vaccine, $\mathrm{n}(\%)$} \\
\hline Yes & $9(7)$ & $6(9)$ \\
\hline No & $92(68)$ & $41(59)$ \\
\hline Unknown & $35(26)$ & $23(33)$ \\
\hline Stratum 1 - HPV 16 mono-infections & $56(41)$ & $29(41)$ \\
\hline Stratum $2^{\mathrm{b}}$ & $80(59)$ & $41(57)$ \\
\hline Single genotype & $27(34)$ & $12(29)$ \\
\hline Multiple genotypes & $53(66)$ & $29(71)$ \\
\hline \multicolumn{3}{|c|}{$\begin{array}{l}\text { a Omitted from ITT population to create modified ITT (mITT) population for analysis. } \\
\text { b Stratum } 2 \text { could be one of } 7 \text { different combinations: } \\
\text { 1. HPV } 16 \text { AND one or more of } 31,33,35,52,58 \text {. } \\
\text { 2. One or more of } 31,33,35,52,58 \text {. } \\
\text { 3. One or more of } 18,39,45,59,68 \text {. } \\
\text { 4. HPV } 16 \text { AND } 18,39,45,59,51,56,68 \text { AND one or more of } 31,33,35,52,58 \text {. } \\
\text { 5. One or more of HPV } 18,39,45,59,51,56,68 \text { AND one or more of } 31,33,35,52,58 \text {. } \\
\text { 6. HPV } 16 \text { AND one or more of } 31,33,35,51,52,56,58,66,73,82 \text {. } \\
\text { 7. Other combinations of single or multiple genotypes not listed above. }\end{array}$} \\
\hline
\end{tabular}

at baseline, as well as race/ethnicity, and number of biopsies. Secondary endpoints included viral DNA clearance of baseline HPV over 2.5 years, as well as long term safety.

\subsection{Statistical analyses}

The population for safety analysis comprised all women who received either vaccine or placebo injections regardless of study completion. The analysis of efficacy for the study did not have a predefined per-protocol population. The main analysis population was a modified intent to treat (MITT) population defined as only patients who are confirmed to have CIN 2/3 at baseline by the CPR panel and who completed at least the six -onth follow-up surgical excision.

The sample size was not determined by a formal power calculation but is based on a feasibility assessment of possible patient recruitment and the likely distribution of HPV types. An interim administrative look (IAL) was performed on the month 6 consensus histology diagnoses and was based on a Bayesian assessment of the predictive probability of success in a phase III trial given the interim results. The predefined analysis plan was developed for completion regardless of the IAL decision.

We explored the following null and alternative hypotheses: the treatment resolution rate is $<60 \%$ or the treatment resolution rate is less than double the control resolution rate, compared to whether the treatment resolution rate is at least $60 \%$ and the treatment resolution rate is at least double the control resolution rate. The $60 \%$ resolution rate was considered the lowest clinically acceptable rate given that surgical cures range from 75 to $100 \%$ [2].

Descriptive analyses corresponded to a priori and post hoc stratification variables: by age ( $>30$ years old vs $\leq 30$ years old), and by baseline diagnosis (CIN2 vs CIN3) and by HPV infection types (HPV 16 monoinfection, HPV16 infection with any of the other 12 HR HPV types, non-HPV16 HR infections and all 13 HR HPV types). Statistical significance was reported at the $p<0.05$ and $p<0.01$ levels for chisquare and Fisher's exact test.

Univariate and multivariate logistic regression were used to evaluate a priori and post hoc impact of the treatment with and without adjustment on age, HPV16 status, HPV type, CIN grade, ethnicity/race, number of biopsies and number of quadrants of disease at baseline. Wald 95\% confidence intervals are reported for individual rates and odds ratios with significance at $p<0.05$.

Viral DNA clearance time was presented using Kaplan-Meier curves where unstratified log-rank tests were used to compare treatment groups by a priori and post hoc stratification. All calculations were performed with SAS 9.4 [23] with significance at $\mathrm{p}<0.05$.

\section{Results}

700 patients were screened with 206 meeting study eligibility (Fig. 1) between August 2009 and September 2013 (last patient last visit). The intent to treat (ITT) safety population included 136 study subjects who received TS vaccine and 70 who received placebo; 56 subjects were in Stratum 1 (HPV 16 monoinfection) and received vaccine and 29 received placebo. Stratum 2 enrolled 80 to vaccine and 41 to placebo. Table 1 shows equitable distributions between treatment groups for age, race, body mass index (BMI), CIN2/3 distribution and strata allocation in this population.

The modified intent to treat ( $\mathrm{MITT}$ ) population received at least one dose of vaccine and had a confirmed entry biopsy of CIN 2 or 3 by CPR panel, resulting in 129 subjects receiving vaccine vs. 63 receiving placebo. In the HPV16 monoinfection stratum, 55 were randomized to the vaccine and 27 to placebo; in stratum 2,74 were randomized to vaccine and 36 to placebo.

\subsection{Primary aim (Table 2)}

Histologic complete resolution from CIN 2/3 at month 6, among the HPV 16 monoinfected women occurred in $18 \%$ (95\% CI: 8-28\%) of the vaccine group compared to $4 \%$ ( $95 \% \mathrm{CI}: 0-11 \%)$ of the placebo group, resulting in a vaccine efficacy of $80 \%$ (95\% CI: $67-88 \%$ ).

Other exploratory histologic endpoints at month 6 for women infected with at least HPV 16 and any other HR HPV type showed complete resolution from $\mathrm{CIN} 2 / 3$ in $18 \%$ (95\% CI: 4-32\%) of the vaccine group vs. $8 \%$ (95\% CI: $-7-24 \%$ ) of the placebo group, with a vaccine efficacy of 53\% (95\% CI: 47-61\%). Complete resolution of women with CIN $2 / 3$ who were infected with any number of HPV infections that are any HR HPV type except HPV 16 occurred in 35\% (95\% CI: 21-49\%) of the vaccine group and $17 \%$ (95\% CI: $2-32 \%$ ) of the placebo group, with a vaccine efficacy of $52 \%$ (95\% CI: 38-66\%). Within this HPV infected group complete resolution of CIN 3 alone occurred significantly more often $(p<0.05)$ in the vaccine group (36\% (95\% CI: 46-57\%)) than the placebo group (0\% (95\% CI: $-2-2 \%)$ ), with a vaccine efficacy of $100 \%$ (95\% CI: 85-100\%). When all HR HPV types were considered, complete resolution from CIN 2/3 occurred significantly more often in the vaccine group (24\% (95\% CI: $17-31 \%)$ ) than the placebo group (10\% (95\% CI: $2-17 \%))(p<0.05)$, with a vaccine efficacy of $60 \%$ (95\% CI: $54-67 \%)$. For the subset of women with any HR HPV type and a CIN 3 baseline lesion, complete resolution occurred significantly more often in the vaccine group (21\% (95\% CI: $12-30 \%)$ ) than the placebo group (0\% (95\% $\mathrm{CI}:-2-2 \%))(p<0.01)$, with a vaccine efficacy of $100 \%(95 \% \mathrm{CI}$ : $95-100 \%)$. The complete resolution rate never exceeded the a priori $60 \%$ threshold, but the vaccine induced resolution rates exceeded 
Safety Population - Randomly Dosed 2:1 (N=206)
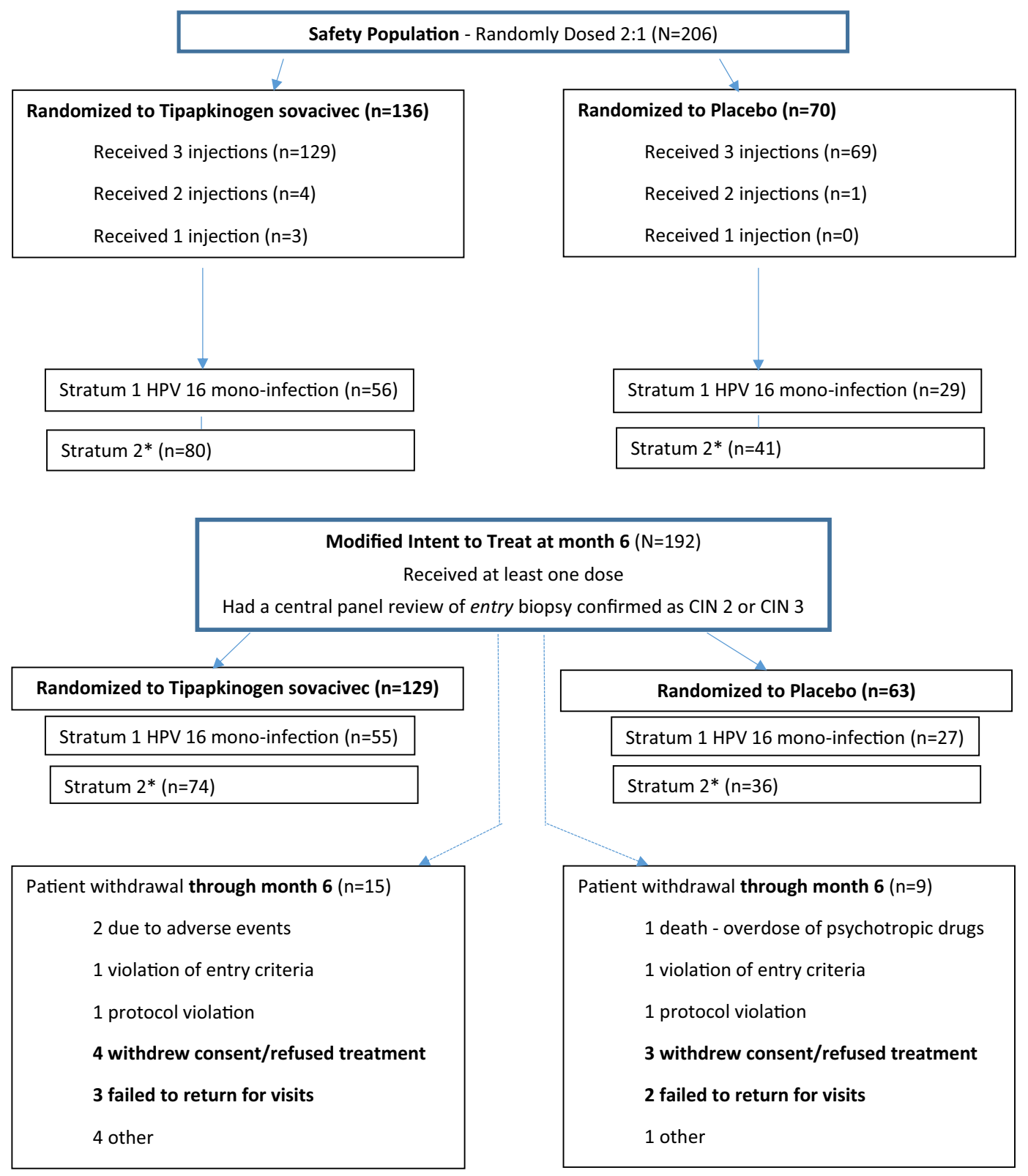

Fig. 1. Trial schematic-700 Patients Screened and subsequent enrollment in the safety population and the modified intent to treat (mITT) population.

twice the placebo rates, meeting part of the a priori hypothesis, in four subgroups: the stratum 1 HPV16 monoinfection for both the CIN 2/3 and CIN 3 populations as well as the non-HPV 16 infections and all HR HPV infections for the CIN 3 population (Supplemental Figure S1).

Histologic partial response at month six was never significantly different between vaccine and placebo groups for any HR HPV stratum. When combining the histologic complete resolution and partial response rates together, the women with CIN 3 associated with any HR HPV type had a significantly higher resolution/response rate of $32 \%$ in the vaccinated group vs. $12 \%$ in the placebo group ( $<<0.01$ ); in addition, women with CIN $2 / 3$ associated with any HR HPV type had a $36 \%$ resolution/response rate vs. $21 \%$ in the placebo group $(p<0.05)$.

\subsection{Logistic regression predictions}

\subsubsection{Univariate}

Three univariate models were explored (Table 3). The first two models explored complete resolution vs. no response in two populations: a) among both CIN 2 and 3 baseline lesions, b) among only CIN 3 baseline lesions. In the first model, regardless of treatment, HPV 16 infections were significantly less likely to resolve than any other HR HPV type (OR $=0.42$ (95\% CI: 0.20-0.88)); and those with three biopsies at baseline were significantly more likely to resolve compared to those with a single diagnostic biopsy ( $\mathrm{OR}=3.17$ (95\% CI: 1.03-9.75)). Among only CIN 3 women, those of Hispanic ethnicity/race were significantly more likely to completely resolve their lesion vs. non-Hispanic white women (OR = 10.64 (95\% CI: 3.00-37.73)); and women with three biopsies at baseline were also significantly more likely to have lesion resolution compared to a single biopsy ( $\mathrm{OR}=5.36(95 \% \mathrm{Cl}$ : $1.14-25.26)$ ).

The third univariate model explored the combination of complete resolution and response vs. no response for the CIN 2/3 baseline. In this model, only ethnicity/race showed significance in resolution/response at month six.

\subsubsection{Multivariate}

There were three corresponding multivariate models adjusting for all single univariate factors. The first multivariate model showed that vaccine treatment significantly increased the odds of complete 
Table 2

Six-month primary endpoints of complete resolution and partial response, mITT population.

\begin{tabular}{|c|c|c|c|c|c|c|c|}
\hline & \multicolumn{3}{|c|}{ Tipapkinogen Sovacivec } & \multicolumn{3}{|l|}{ Placebo } & \multirow[b]{2}{*}{$\begin{array}{l}\text { Vaccine efficacy }{ }^{\mathrm{a}} \text { for complete } \\
\text { resolution } \\
\%(95 \% \mathrm{CI})\end{array}$} \\
\hline & $\begin{array}{l}\text { Complete } \\
\text { resolution }\end{array}$ & $\begin{array}{l}\text { Partial } \\
\text { response }\end{array}$ & $\begin{array}{l}\text { No } \\
\text { response }\end{array}$ & $\begin{array}{l}\text { Complete } \\
\text { resolution }\end{array}$ & $\begin{array}{l}\text { Partial } \\
\text { response }\end{array}$ & $\begin{array}{l}\text { No } \\
\text { response }\end{array}$ & \\
\hline \multirow{3}{*}{ HPV 16 mono infection } & $10 / 55$ & $7 / 55$ & $38 / 55$ & $1 / 27$ & $5 / 27$ & $21 / 27$ & $80 \%$ \\
\hline & $(18.2 \%)$ & $(12.7 \%)$ & (69.1\%) & $(3.7 \%)$ & $(18.5 \%)$ & $(77.8 \%)$ & $(67-88 \%)$ \\
\hline & $6 / 32$ & $4 / 32$ & $22 / 32$ & $0 / 14$ & $2 / 14$ & $12 / 14$ & \\
\hline \multirow{2}{*}{ Age: $\leq 30$ yrs } & $(18.8 \%)$ & $(12.5 \%)$ & $(68.8 \%)$ & $(0.0 \%)$ & $(14.3 \%)$ & $(85.7 \%)$ & \\
\hline & $4 / 23$ & $3 / 23$ & $16 / 23$ & $1 / 13$ & $3 / 13$ & $9 / 13$ & \\
\hline \multirow[t]{2}{*}{ Age: $>30$ yrs } & $(17.4 \%)$ & $(13.0 \%)$ & $(69.6 \%)$ & $(7.7 \%)$ & $(23.1 \%)$ & $(69.2 \%)$ & \\
\hline & $4 / 16$ & $1 / 16$ & $11 / 16$ & $1 / 9$ & $2 / 9$ & $6 / 9$ & \\
\hline \multirow[t]{2}{*}{ CIN2 } & $(25.0 \%)$ & $(6.3 \%)$ & $(68.8 \%)$ & $(11.1 \%)$ & $(22.2 \%)$ & $(66.7 \%)$ & \\
\hline & $6 / 39$ & $6 / 39$ & $27 / 39$ & $0 / 18$ & $3 / 18$ & $15 / 18$ & $100 \%$ \\
\hline \multirow[t]{2}{*}{ CIN3 } & $(15.4 \%)$ & $(15.4 \%)$ & $(69.2 \%)$ & $(0.0 \%)$ & $(16.7 \%)$ & $(83.3 \%)$ & $(91-100 \%)$ \\
\hline & $5 / 28$ & $4 / 28$ & $19 / 28$ & $1 / 12$ & $0 / 12$ & $11 / 12$ & $53 \%$ \\
\hline \multirow[t]{2}{*}{ HPV 16 infection with any other HR HPV type } & $(17.9 \%)$ & $(14.3 \%)$ & $(67.9 \%)$ & $(8.3 \%)$ & $(0.0 \%)$ & $(91.7 \%)$ & $(47-61 \%)$ \\
\hline & $3 / 20$ & $4 / 20$ & $13 / 20$ & $1 / 8$ & $0 / 8$ & $7 / 8$ & \\
\hline \multirow[t]{2}{*}{ Age: $\leq 30$ yrs } & $(15.0 \%)$ & $(20.0 \%)$ & $(65.0 \%)$ & $(12.5 \%)$ & $(0.0 \%)$ & $(87.5 \%)$ & \\
\hline & $2 / 8$ & $0 / 8$ & $6 / 8$ & $0 / 4$ & $0 / 4$ & $4 / 4$ & \\
\hline \multirow[t]{2}{*}{ Age: $>30$ yrs } & $(25.0 \%)$ & $(0.0 \%)$ & $(75.0 \%)$ & $(0.0 \%)$ & $(0.0 \%)$ & $(100.0 \%)$ & \\
\hline & $3 / 13$ & $3 / 13$ & $7 / 13$ & $1 / 8$ & $0 / 8$ & $7 / 8$ & \\
\hline \multirow[t]{2}{*}{ CIN2 } & $(23.1 \%)$ & $(23.1 \%)$ & $(53.8 \%)$ & $(12.5 \%)$ & $(0.0 \%)$ & $(87.5 \%)$ & \\
\hline & $2 / 15$ & $1 / 15$ & $12 / 15$ & $0 / 4$ & $0 / 4$ & $4 / 4$ & $100 \%$ \\
\hline CIN3 & $(13.3 \%)$ & $(6.7 \%)$ & $(80.0 \%)$ & $(0.0 \%)$ & $(0.0 \%)$ & $(100.0 \%)$ & $(80-100 \%)$ \\
\hline \multirow{3}{*}{$\begin{array}{l}\text { Non-HPV } 16 \text { infections of any HR HPV type and } \\
\text { number of types }\end{array}$} & $16 / 46$ & $4 / 46$ & $26 / 46$ & $4 / 24$ & $2 / 24$ & $18 / 24$ & $52 \%$ \\
\hline & $(34.8 \%)$ & $(8.7 \%)$ & $(56.5 \%)$ & $(16.7 \%)$ & $(8.3 \%)$ & $(75.0 \%)$ & $(38-66 \%)$ \\
\hline & $8 / 27$ & $3 / 27$ & $16 / 27$ & $3 / 16$ & $1 / 16$ & $12 / 16$ & \\
\hline \multirow[t]{2}{*}{ Age: $\leq 30$ yrs } & $(29.6 \%)$ & $(11.1 \%)$ & $(59.3 \%)$ & $(18.8 \%)$ & $(6.3 \%)$ & $(75.0 \%)$ & \\
\hline & $8 / 19$ & $1 / 19$ & $10 / 19$ & $1 / 8$ & $1 / 8$ & $6 / 8$ & \\
\hline \multirow[t]{2}{*}{ Age: > 30 yrs } & $(42.1 \%)$ & $(5.3 \%)$ & $(52.6 \%)$ & $(12.5 \%)$ & $(12.5 \%)$ & $(75.0 \%)$ & \\
\hline & $8 / 24$ & $3 / 24$ & $13 / 24$ & $4 / 13$ & $1 / 13$ & $8 / 13$ & \\
\hline \multirow[t]{2}{*}{ CIN2 } & $(33.3 \%)$ & $(12.5 \%)$ & $(54.2 \%)$ & $(30.8 \%)$ & $(7.7 \%)$ & $(61.5 \%)$ & \\
\hline & $8 / 22$ & $1 / 22$ & $13 / 22$ & 0/11 & $1 / 11$ & $10 / 11$ & $100 \%$ \\
\hline \multirow[t]{2}{*}{$\mathrm{CIN}^{*}$} & $(36.4 \%)$ & $(4.5 \%)$ & (59.1\%) & $(0.0 \%)$ & $(9.1 \%)$ & $(90.9 \%)$ & $(85-100 \%)$ \\
\hline & $31 / 129$ & $15 / 129$ & $83 / 129$ & $6 / 63$ & $7 / 63$ & $50 / 63$ & $60 \%$ \\
\hline \multirow[t]{2}{*}{ All HR HPV ${ }^{\mathrm{b}}$ types* } & $(24.0 \%)$ & (11.6\%) & $(64.3 \%)$ & $(9.5 \%)$ & (11.1\%) & $(79.4 \%)$ & (54-67\%) \\
\hline & $17 / 79$ & $11 / 79$ & $51 / 79$ & $4 / 38$ & $3 / 38$ & $31 / 38$ & \\
\hline \multirow[t]{2}{*}{ Age: $\leq 30$ yrs } & $(21.5 \%)$ & $(13.9 \%)$ & $(64.6 \%)$ & (10.5\%) & $(7.9 \%)$ & $(81.6 \%)$ & \\
\hline & $14 / 50$ & $4 / 50$ & $32 / 50$ & $2 / 25$ & $4 / 25$ & $19 / 25$ & \\
\hline \multirow[t]{2}{*}{ Age: $>30$ yrs } & $(28.0 \%)$ & $(8.0 \%)$ & $(64.0 \%)$ & $(8.0 \%)$ & $(16.0 \%)$ & $(76.0 \%)$ & \\
\hline & $15 / 53$ & $7 / 53$ & $31 / 53$ & $6 / 30$ & $3 / 30$ & $21 / 30$ & \\
\hline \multirow[t]{2}{*}{ CIN2 } & $(28.3 \%)$ & $(13.2 \%)$ & $(58.5 \%)$ & $(20.0 \%)$ & $(10.0 \%)$ & $(70.0 \%)$ & \\
\hline & $16 / 76$ & $8 / 76$ & $52 / 76$ & $0 / 33$ & $4 / 33$ & $29 / 33$ & $100 \%$ \\
\hline CIN3 ${ }^{* *}$ & (21.1\%) & $(10.5 \%)$ & $(68.4 \%)$ & $(0.0 \%)$ & $(12.1 \%)$ & $(87.9 \%)$ & $(95-100 \%)$ \\
\hline
\end{tabular}

a Vaccine efficacy is calculated as the ratio of the difference between the rates of complete resolution of the lesion at month 6 with placebo from the rate from treatment with

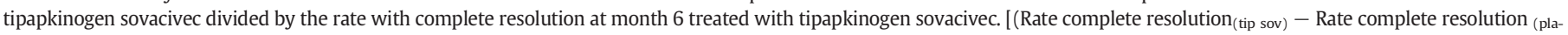
cebo) / ( Rate complete resolution (tip sov) )].

b All HRHPV means regardless of high risk human papillomavirus type of the 13 types for which we tested.

${ }^{*} p<0.05$ in comparison to respective placebo.

** $p<0.01$.

resolution among the $\mathrm{CIN} 2 / 3$ baseline population $(\mathrm{aOR}=4.68(95 \% \mathrm{CI}$ : 1.57-13.98)), and Hispanic women were significantly more likely to completely resolve their CIN $2 / 3$ lesion at month six than nonHispanic white women $(\mathrm{aOR}=3.11$ (95\% CI: $1.21-8.02)$ ).

The second multivariate model considered all factors in prediction of CIN 3 resolution. Because there were zero complete resolutions in the placebo group, an adjusted model for vaccine effects was not possible. Significant racial differences were seen in complete resolution.

The third multivariate model was similar to the first in that the vaccine treatment significantly increased odds of complete resolution or partial response at month six among the CIN $2 / 3$ baseline population $(\mathrm{aOR}=2.82(95 \% \mathrm{Cl}: 1.26-6.30))$, but only non-Hispanic Black women remained significantly more likely that non-Hispanic White women to resolve/respond ( $\mathrm{aOR}=5.91$ (95\% CI: 1.78-19.55)). Of note, in all multivariate models the type of HPV infection did not significantly predict month six resolution or response.

\subsubsection{5 year follow-up}

While all women were to be followed to study end, few subjects needed to be histologically evaluated during this time frame (Table 4).
Of those who had complete resolution at month 6, 24\% (4/17) in the TS arm had worse histology detected at 2.5 years. Likewise, one of two (50\%) placebo subjects had worse histology at longer term follow-up.

Of those who had partial response at month 6, 12\% (3/25) in the TS arm had worse histology detected at follow up; while one of three (33\%) placebo subjects had worse histology at follow-up.

This long-term follow-up study resulted in a mean follow-up time of 822 days for the treatment group and 756 days for the placebo group with $76 \%$ of the treatment group and $66 \%$ of the placebo group staying in the study for $>811$ days.

\subsection{Secondary aim}

Viral DNA clearance of all CIN 2/3 regardless of HR HPV type (Fig. 2A) was significantly greater in the vaccine treated cohort than in placebo cohort ( $p<0.01)$; in addition, Fig. 2B shows that viral DNA clearance among the women with baseline CIN 3, regardless of HR HPV type, was significantly superior with vaccine than placebo $(p \leq 0.01)$. For specific HR HPV types (Fig. 2C), the vaccine was superior to placebo for the following subgroups: 1) the stratum 1 cohort of HPV 16 monoinfected 


\begin{tabular}{|c|c|c|c|c|c|c|}
\hline & \multicolumn{2}{|c|}{$\begin{array}{l}\text { Among CIN } 2 / 3 \\
\text { Predicting complete resolution vs. } \\
\text { no response }\end{array}$} & \multicolumn{2}{|c|}{$\begin{array}{l}\text { Among CIN } 3 \\
\text { Predicting complete resolution vs. } \\
\text { no response }\end{array}$} & \multicolumn{2}{|c|}{$\begin{array}{l}\text { Among CIN } 2 / 3 \\
\text { Predicting complete resolution and } \\
\text { partial response vs. no response }\end{array}$} \\
\hline & OR $(95 \% \mathrm{CI})$ & $\mathrm{aOR}(95 \% \mathrm{Cl})$ & OR $(95 \% \mathrm{Cl})$ & $\mathrm{aOR}(95 \% \mathrm{CI})$ & OR $(95 \% \mathrm{CI})$ & $\mathrm{aOR}(95 \% \mathrm{Cl})$ \\
\hline \multirow[t]{2}{*}{ Vaccine } & 3.11 & 4.68 & $\mathrm{NE}$ & $\mathrm{NE}$ & 2.13 & 2.82 \\
\hline & $1.21-7.98$ & $1.57-13.98$ & & & $1.05-4.33$ & $1.26-6.30$ \\
\hline Placebo & Referent & Referent & Referent & Referent & Referent & Referent \\
\hline \multicolumn{7}{|l|}{ HPV 16} \\
\hline Placebo & Referent & & & & Referent & Referent \\
\hline \multicolumn{7}{|l|}{ HPV infection type } \\
\hline \multirow[t]{2}{*}{ HPV 16} & 0.42 & 0.42 & 0.40 & 0.37 & 0.63 & 0.68 \\
\hline & $0.20-0.88$ & $0.18-1.01$ & $0.13-1.18$ & $0.09-1.57$ & $0.33-1.18$ & $0.33-1.39$ \\
\hline Non HPV 16 & Referent & Referent & Referent & Referent & Referent & Referent \\
\hline \multirow[t]{2}{*}{ Age } & 1.02 & 1.05 & 1.03 & 1.02 & 1.02 & 1.04 \\
\hline & $0.97-1.07$ & $0.99-1.11$ & $0.96-1.10$ & $0.93-1.12$ & $0.98-1.06$ & $1.00-1.09$ \\
\hline \multirow{3}{*}{ Black } & Referent & Referent & Referent & Referent & Referent & Referent \\
\hline & 3.07 & 4.42 & 6.50 & 5.10 & 4.10 & 5.91 \\
\hline & $0.82-11.51$ & $0.99-19.79$ & $0.95-44.59$ & $0.61-42.77$ & $1.41-11.88$ & $1.78-19.55$ \\
\hline \multirow[t]{2}{*}{ Hispanic } & 3.49 & 3.11 & 10.64 & 6.22 & 2.55 & 2.07 \\
\hline & $1.49-8.19$ & $1.21-8.02$ & $3.00-37.73$ & $1.47-26.23$ & $1.18-5.50$ & $0.91-4.71$ \\
\hline \multirow[t]{2}{*}{ Other } & 1.34 & 1.18 & & & 1.59 & 1.40 \\
\hline & $0.14-12.67$ & $0.11-12.50$ & & & $0.28-9.11$ & $0.22-8.82$ \\
\hline \multicolumn{7}{|c|}{ Number of biopsies } \\
\hline One biopsy & Referent & Referent & Referent & Referent & Referent & Referent \\
\hline \multirow[t]{2}{*}{ Two biopsies } & 1.60 & 2.82 & 1.25 & 1.43 & 1.34 & 2.00 \\
\hline & $0.67-3.83$ & $0.94-8.49$ & $0.34-4.66$ & $0.26-7.91$ & $0.66-2.69$ & $0.87-4.60$ \\
\hline \multirow[t]{2}{*}{ Three biopsies } & 3.17 & 3.75 & 5.36 & 3.41 & 2.10 & 2.51 \\
\hline & $1.03-9.75$ & $0.93-15.10$ & $1.14-25.26$ & $0.44-26.57$ & $0.79-5.60$ & $0.79-7.90$ \\
\hline Four biopsies & 1.85 & 1.56 & & & 1.96 & 3.36 \\
\hline \multicolumn{7}{|c|}{ Number of quadrants of disease } \\
\hline
\end{tabular}

NE means not evaluable.

women, 2) the cohort with any HR HPV infection except HPV 16, and 3 ) the cohort of HPV16 co-infected with any other HR HPV infection.

\subsection{Safety}

In general, the TS vaccine was well tolerated but with nearly all recipients having an injection site reaction, $29 \%$ being graded as severe according to the FDA Guidance for Industry: Toxicity Grading Scale for Healthy Adult and Adolescent Volunteers Enrolled in Preventative Vaccine Clinical Trials and Common Terminology Criteria for Adverse Events v3.0, for which two patients discontinued the study (Supplemental Table S1). Of the patients who received placebo, 37\% experienced injection site reactions graded as mild, moderate, or severe. All other adverse events or pregnancy outcomes were evenly distributed between the treatment groups. One death occurred in the placebo arm of the study (due to medication overdose) approximately six months after the last study injection; the death was considered unrelated to the study drug. One subject reported severe lymphadenopathy after the first two injections, delaying the third TS injection. One subject in the placebo arm reported invasive lobular breast carcinoma detected prior to month 3 .

There were six cancers and three adenocarcinoma-in-situ diagnoses detected between the time of the trial injections (vaccine/placebo) and the six-month excision. All three adenocarcinoma-in-situ were in the placebo arm. Three squamous cell cancers were detected in the vaccine arm, and three cancers (one each: adenosquamous, adeno, and squamous) were detected in the placebo arm. Risk factor analyses of these cancers are discussed in the supplement.

\section{Discussion}

Our study is the largest study to date following women for the longest time frame trialing a therapeutic vaccine for HPV associated CIN $2 / 3$. The TS vaccine was significantly associated with greater complete resolution rates of histologic CIN 3 disease as well as with significantly greater viral DNA resolution regardless of HR HPV type. The vaccine was expected to act in the HPV 16 alpha 9 clade as determined in phase 1 studies by $\mathrm{T}$ cell proliferation, anti-MVA antibodies and antiE6/E7 neutralizing antibodies [4], but this work shows that all HR HPV types responded to some degree to the vaccine. This presents the hypothesis that CIN 3, the most severe dysplasia, with greater expression of E6/E7 proteins are susceptible to the neutralizing antibodies significantly more than the CIN 2 lesions, and that this immunotherapy might be combined with other checkpoint inhibitors for more advanced stages of HPV associated cancers that are expressing E6/E7 proteins.

We showed significant complete resolution of CIN 2/3 from all HR HPV types at $24 \%$ in the vaccine group, similar to a pilot report by Alvarez showing a 26\% complete resolution of HPV 16 CIN 2/3 lesions after particle mediated epidermal delivery, intramuscular delivery or intralesional delivery of a DNA based therapeutic HPV 16 E7-calreticulin based compound [1]; and similar to a phase 1 trial of HPV16 E6 adjuvanted with candida (Pepcan) that resulted in 17\%-20\% complete resolution at higher 
Table 4

Histologic follow up through month 30 in mITT population.

\begin{tabular}{|c|c|c|}
\hline & \multirow{2}{*}{$\begin{array}{l}\text { Tipapkinogen } \\
\text { Sovacivec } \\
N=129\end{array}$} & \multirow{2}{*}{$\begin{array}{l}\text { Placebo } \\
N=63\end{array}$} \\
\hline & & \\
\hline $\begin{array}{r}\text { Histological assessments } \\
\text { available post month } 6\end{array}$ & $57 / 129(44 \%)$ & $24 / 63(38 \%)$ \\
\hline $\begin{array}{l}\text { Histological assessments } \\
\text { available post month } 6 \text { for } \\
\text { those subjects who had } \\
\text { complete resolution at month } \\
6\end{array}$ & $17 / 31(22 \%)$ & $2 / 6(33 \%)$ \\
\hline $\begin{array}{l}\text { Subjects with complete } \\
\text { resolution at month } 6 \text { who } \\
\text { had worse histology at } 2.5 \\
\text { years }\end{array}$ & $4 / 17(24 \%)$ & $1 / 2(50 \%)$ \\
\hline Histology at 2.5 years & $\begin{array}{c}1 \text { subject: CIN } \\
1 \\
1 \text { subject: CIN } \\
2 \\
2 \text { subjects: } \\
\text { CIN 3 }\end{array}$ & $\begin{array}{c}1 \text { subject: adenocarcinoma in } \\
\text { situ }\end{array}$ \\
\hline $\begin{array}{l}\text { Histological assessment } \\
\text { available post month } 6 \text { for } \\
\text { those subjects who had partial } \\
\text { response at month } 6\end{array}$ & $25 / 46(54 \%)$ & $3 / 13(23 \%)$ \\
\hline $\begin{array}{l}\text { Subjects with a partial response } \\
\text { at month } 6 \text { who had worse } \\
\text { histology at } 2.5 \text { years }\end{array}$ & $3 / 25(12 \%)$ & $1 / 3(33 \%)$ \\
\hline Histology at 2.5 years & $\begin{array}{l}1 \text { subject: CIN } \\
2 \\
2 \text { subjects: } \\
\text { CIN } 3\end{array}$ & $\begin{array}{c}1 \text { subject: intracervical } \\
\text { carcinoma with stromal } \\
\text { invasion, squamous cell } \\
\text { carcinoma }\end{array}$ \\
\hline
\end{tabular}

doses [15]. Two small phase 2 trials with a heat shock fusion protein (SGN-00101) [12,21] and a compound similar to TS (TG4001) did not reach complete resolution [28]. In addition, the placebo complete resolution rate (10\%) and partial response (11\%) at month 6 for all HR HPV types were similar to other immunotherapeutic studies for CIN2/3 [20].

The absolute complete resolution rate did not meet the a priori primary objective, in our study, of $60 \%$, which was identified as a clinically acceptable resolution threshold, but the therapeutic vaccine did meet the resolution rate above twice the placebo resolution rate for HPV 16 monoinfected CIN 2/3 and for all HR HPV CIN 3 lesions. Given the therapeutic harms of surgical excision [17-19] with reproductive morbidity, an argument can be made that a lower therapeutic resolution/response could be both clinically and cost effective from a broader perspective than just cancer prevention.

The combination complete resolution/partial response rates in our study (36\%) are similar to the $40 \%$ regression rate documented for VGX-3100 against CIN2/3 associated with HPV 16/18 in a phase $2 \mathrm{~b}$ trial [28]; to that seen by Pepcan in a phase 1 trial [15]; and to the $48 \%$ partial resolution seen in the phase 2 TG4001 trial [12].

We cannot know from this study if a higher resolution rate could have been seen if the endpoint had been evaluated later than month 6. For instance, another immunotherapeutic agent, VGX-3100, showed a marginally higher efficacy for CIN2/3 associated with HPV 16/18 regression to normal at month 9 , but likewise did not meet the $60 \%$ resolution threshold [28]. In addition, we did not test whether a booster vaccination at month 3 could have increased month 6 resolution rates; nor did we test whether fewer than three doses could accomplish the same current resolution or response.

Of those with resolution or response post-surgical treatment only a small proportion of subjects had worsening pathology at 2.5 years follow-up most likely due to incomplete excision of the original lesion. Of the $2.9 \%$ of enrolled subjects diagnosed with a malignancy, it is likely that these were prevalent cancers missed at diagnosis, supported by the literature which shows an incident rate of $2.0-4.1 \%$ due to the limitations of colposcopy-guided biopsies [7,14].
Viral DNA clearance is a secondary indicator of efficacy. Prior work indicates that women who have viral DNA clearance of their type specific persistent HPV infection are more likely to maintain resolution of their CIN2/3 [26]. In addition, women with surgical excisions resulting in positive endocervical margins have more than two-fold the recurrence rates of CIN 2/3 because of residual viral infection [8]. Unlike the VGX-3100 study [28], viral DNA clearance in our study was measured and analyzed separately from histologic resolution/response. Our vaccine was significantly superior to placebo in complete viral DNA clearance for both CIN 2/3 and CIN 3 for all HR HPV types considered, although it did not provide complete clearance in all subjects. Complete viral DNA clearance was sustained over the 2.5 year follow-up in both vaccine and placebo groups.

This study has several strengths. A simple subcutaneous injection is an easy implementation strategy. Even with less resolution/response than anticipated, this vaccine could offer a preliminary reduction in surgical excisions avoiding their resulting reproductive morbidity harms. In addition, this study had a rigorous adjudicating CPR to review all histologic specimens reducing the misdiagnosis at study entry. The precise HPV detection methodology allowed both HPV 16 monoinfection and other HR HPV types to be detected from all sample aliquots. The rigorous study design protected subjects by detecting the prevalent cancers without impacting trial results. Finally, most of the study participants were followed for a 30-month time frame, the longest duration of follow-up in a therapeutic vaccine trial to date.

The study also has limitations. The study was not powered for a specific efficacy; and the baseline viral load could not differentiate incident from persistent infections. Another limitation was the six-month time frame for immunotherapeutic response which, in hindsight, may have been too short. Finally, balancing the potential harm of CIN 3 progressing to cancer with the need to understand the efficacy of an immunotherapeutic agent is challenging even over a short time frame, as the colposcopic impression is maximally sensitive for CIN3+ disease at only $70 \%$ [13].

Immunologic therapeutic HPV vaccines offer a potential nonsurgical option for women with cervical pre-cancers which might be extended to other HPV associated precursors or cancers in the future. The spectrum of decreasing incidence and mortality from HPV associated cancers includes prophylactic vaccination [16], skin barriers such as condoms [10], continued education about sexuality [27], creating potentially hormonally hostile environments [9], with the largest success to date being the opportunistic and organized screening programs simplified most recently by the approval of primary HR HPV screening tests at five-year intervals [29]. The treatment of cervical pre-cancerous lesions may eventually include first round therapeutic vaccination which we have also shown to be safe through 30 months prior to going to excisional surgery if necessary.

\section{Role of funding source}

This study was conceived jointly by F Hoffmann-La Roche LTD and consultants, some of whom also served as investigators. Roche funded and coordinated this study. Roche sold the compound to Transgene who facilitated the data analysis with the corresponding author. The corresponding author had full access to the clinical study report and had final responsibility for submission for the publication.

Supplementary data to this article can be found online at https://doi. org/10.1016/j.ygyno.2019.03.250.

\section{Conflict of interest statement}

Dr. Harper's institution reports grants from Roche during the conduct of the study. Dr. Nieminen reports grants and non-financial support from Roche during the conduct of the study.

Dr. Donders reports nothing to disclose.

Dr. Einstein reports other from Photocure, other from Papivax, other from Cynvec, other from PDS, other from Altum Pharma, other from Becton Dickinson, outside the submitted 
A. Among baseline CIN 2/3 regardless of HR HPV types through month 30, mITT

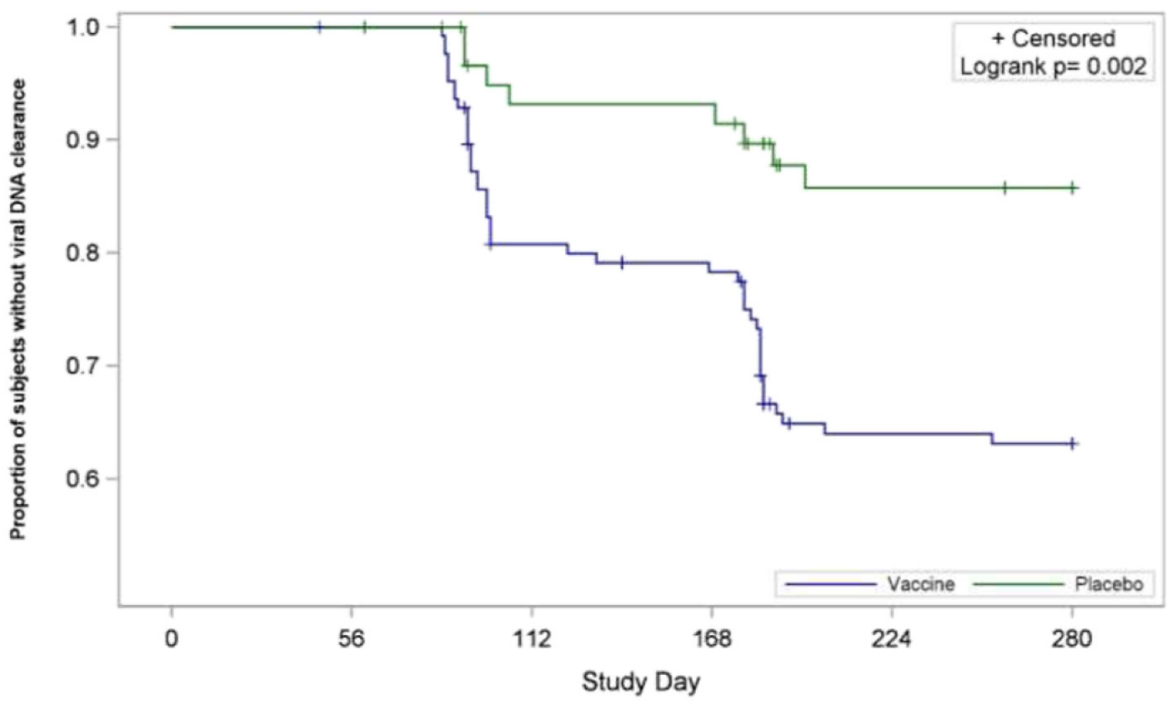

Vaccine

Placebo

127
62

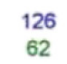

126
62

99
54

95
54

73
43

72
42
B. Among baseline CIN 3 regardless of HR HPV types through month 30, $\mathrm{mITT}$

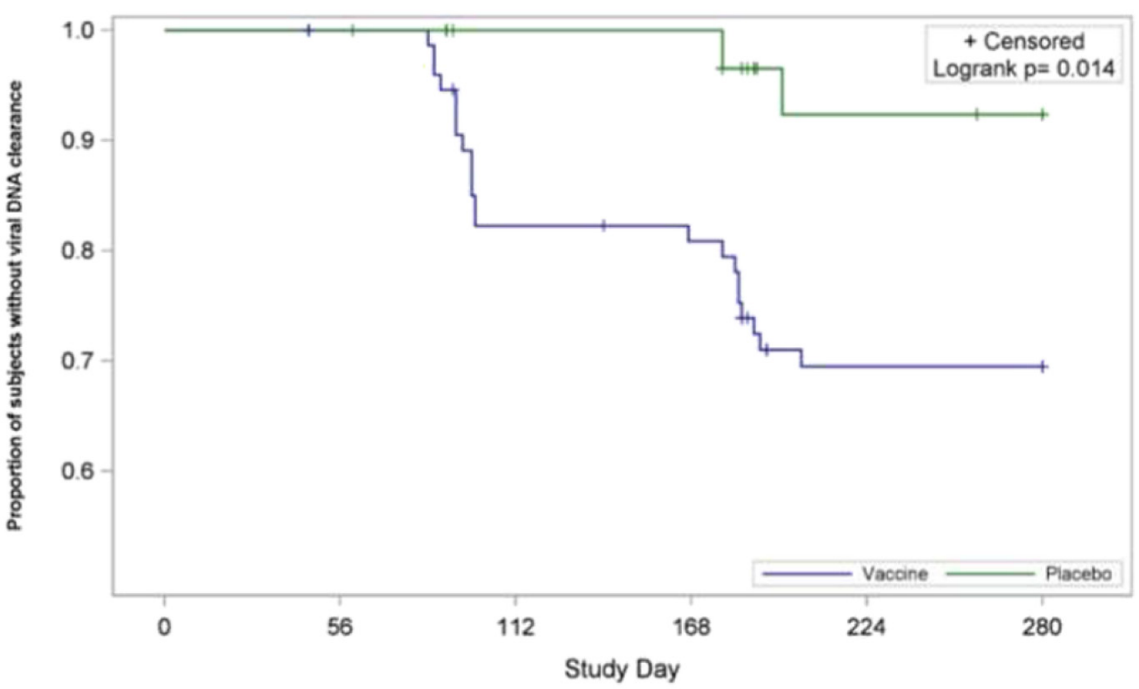

Vaccine

Placebo 32

C. Among baseline CIN 2/3 by HR HPV type through month $30, \mathrm{mITT}$

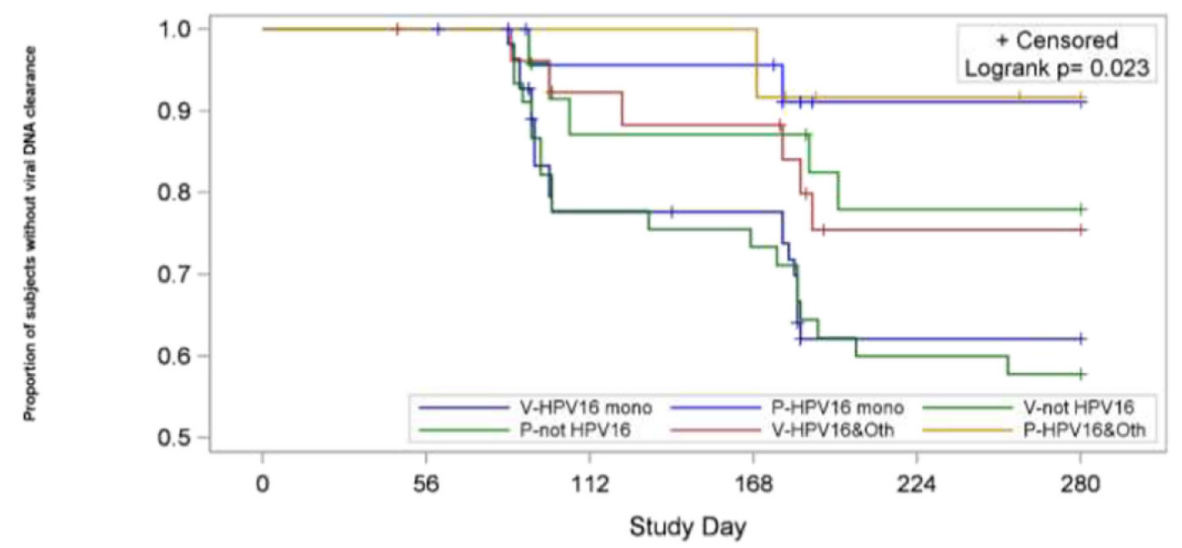

$\begin{array}{rrrrrrr}\text { V-HPV16 mono } & 55 & 55 & 41 & 40 & 30 & 30 \\ \text { P-HPV16 mono } & 26 & 26 & 22 & 22 & 17 & 17 \\ \text { V-not HPV16 } & 45 & 45 & 35 & 33 & 27 & 26 \\ \text { P-not HPV16 } & 24 & 24 & 20 & 20 & 17 & 17 \\ \text { V-HPV168Oth } & 27 & 26 & 23 & 22 & 16 & 16 \\ \text { P-HPV168Oth } & 12 & 12 & 12 & 12 & 9 & 8\end{array}$

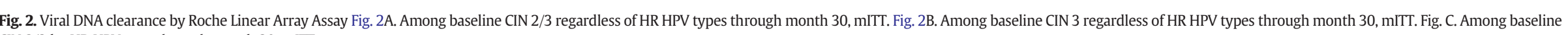
CIN 2/3 by HR HPV type through month 30, mITT. 
work; he has advised or participated in educational speaking activities but does not receive an honorarium from any companies. In specific cases, his employers have received payment for his time spent for these activities from Papivax, Cynvec, Altum Pharma Photocure, Becton Dickenson, and PDS Biotechnologies. If travel required for meetings with industry, the company pays for Dr. Einstein's travel expenses. Rutgers has received grant funding for research-related costs of clinical trials that Dr. Einstein has been the overall or local PI within the past 12 months from J\&J, Pfizer, AstraZeneca, Advaxis, and Inovio.

Dr. Garcia reports grants from Transgene, grants from Roche, during the conduct of the study.

Dr. Huh reports personal fees from Antiva, personal fees from Inovio, outside the submitted work.

Dr. Stoler reports personal fees from Roche, during the conduct of the study; personal fees from Roche, personal fees from Becton Dickinson, personal fees from Merck, personal fees from Inovio Pharmaceuticals, outside the submitted work.

Dr. Glavini reports she is an employee of Roche.

Dr. Attley reports she is an employee of Roche.

Dr. Limacher reports being an employee and shareholder from 2004 to 2016 at Transgene SA, during the conduct of the study.

Mrs. Bastien reports nothing to disclose.

Dr. Calleja reports she was an employee of Roche during the study period.

\section{Author contributions}

DMH, PN, GD, MHE, WKH contributed patients to the trial

$\mathrm{DMH}, \mathrm{KG}, \mathrm{GA}, \mathrm{JML}$, contributed to the literature search.

$\mathrm{DMH}, \mathrm{BB}$ contributed to the figures.

DMH, PN, MHE, FG, WKH, MHS, KG, GA, JML, EC contributed to the study design.

$\mathrm{DMH}, \mathrm{PN}, \mathrm{GD}, \mathrm{WKH}, \mathrm{MHE}, \mathrm{MHS}$, contributed to data collection.

DMH, PN, GD, MHE, FG, WKH, MHS, KG, GA, JML, BB, EC contributed to the data analysis, data interpretation, writing and reviewing of final manuscript.

\section{References}

[1] Alvarez RD, Huh WK, Bae S, Lamb LS Jr, Conner MG, Boyer J, et al. A pilot study of pNGVL4a-CRT/E7(detox) for the treatment of patients with HPV16+ cervical intraepithelial neoplasia 2/3 (CIN2/3). Gynecol. Oncol.. 2016 Feb;140(2):245-52. doi:https://doi.org/10.1016/j.ygyno.2015.11.026.

[2] M. Arbyn, C.W.E. Redman, F. Verdoodt, M. Kyrgiou, M. Tzafetas, S. Ghaem-Maghami, K.U. Petry, S. Leeson, C. Bergeron, P. Nieminen, J. Gondry, O. Reich, E.L. Moss, Incomplete excision of cervical precancer as a predictor of treatment failure: a systematic review and meta-analysis, Lancet Oncol. 18 (12) (2017) 1665-1679, https://doi.org/ 10.1016/S1470-2045(17)30700-3 Dec

[3] F. Bray, J. Ferlay, I. Soerjomataram, R.L. Siegel, L.A. Torre, A. Jemal, Global cancer statistics 2018: GLOBOCAN estimates of incidence and mortality worldwide for 36 cancers in 185 countries, CA Cancer J. Clin. (2018)https://doi.org/10.3322/caac.21492 Sep 12.

[4] J--L. Brun, V. Dalstein, J. Leveque, P. Mathevet, P. Raulic, J.-J. Baldauf, et al., Regression of high-grade cervical intraepithelial neoplasia with TG4001 targeted immunotherapy, Am. J. Obstet. Gynecol. 204 (2011)https://doi.org/10.1016/j.ajog.2010.09.020 169.e1-8.

[5] L. Bruni, M. Diaz, L. Barrionuevo-Rosas, R. Herrero, F. Bray, F.X. Bosch, et al., Global estimates of human papillomavirus vaccination coverage by region and income level: a pooled analysis, Lancet Glob. Health 4 (7) (2016) e453-e463, https://doi. org/10.1016/S2214-109X(16)30099-7 Jul.

[6] L. Bruni, L. Barrionuevo-Rosas, G. Albero, B. Serrano, M. Mena, D. Gómez, J. Muñoz, F.X. Bosch, S. de Sanjosé, ICO/IARC Information Centre on HPV and Cancer (HPV Information Centre). Human Papillomavirus and Related Diseases in Americas. Summary Report 10 December 2018, Dec 2018 (no doi).

[7] Byrom J, Douce G, Jones PW, Tucker H, Millinship J, Dhar K, et al. Should punch biopsies be used when high-grade disease is suspected at initial colposcopic assessment? A prospective study. Int. J. Gynecol. Cancer. 2006 Jan-Feb;16(1):253-6. doi: https://doi.org/10.1111/j.1525-1438.2006.00344.x

[8] H.E. Cejtin, L. Zimmerman, M. Mathews, A. Patel, Predictors of persistent or recurrent disease after loop electrosurgical excision procedure, J. Low. Genit. Tract Dis. 21 (1) (2017) 59-63, https://doi.org/10.1097/LGT.0000000000000276 Jan.
[9] S.H. Chung, M.K. Shin, K.S. Korach, P.F. Lambert, Requirement for stromal estrogen receptor alpha in cervical neoplasia, Horm Cancer 4 (1) (2013 Feb) 50-59, https:// doi.org/10.1007/s12672-012-0125-7 (Epub 2012 Oct 13).

[10] Condoms and STDs, Fact sheet for public health personnel, https://www.cdc.gov/ condomeffectiveness/latex.html 2016.

[11] Dai P, Wang W, Cao H, Avogadri F, Dai L, Drexler I, et al. Modified vaccinia virus Ankara triggers type I IFN production in murine conventional dendritic cells via a cGAS/STING-mediated cytosolic DNA-sensing pathway. PLoS Pathog.. 2014 Apr 17;10(4): e1003989. doi:https://doi.org/10.1371/journal.ppat.1003989

[12] M.H. Einstein, A.S. Kadisha, R.D. Burk, M.Y. Kim, S. Wadlerd, H. Streichere, et al., Heat shock fusion protein-based immunotherapy for treatment of cervical intraepithelial neoplasia III, Gynecol. Oncol. 106 (3) (2007 Sept) 453-460, https://doi.org/10.1016/ j.ygyno.2007.04.038.

[13] Gage JC, Hanson VW, Abbey K, Dippery S, Gardner S, Kubota J, et al. Number of cervical biopsies and sensitivity of colposcopy. Obstet. Gynecol.. 2006 Aug;108(2): 264-72. doi:https://doi.org/10.1097/01.AOG.0000220505.18525.85

[14] E. González-Bosquet, S. Fernandez, S. Sabra, J.M. Lailla, Negative HPV testing among patients with biopsy-proven cervical intraepithelial neoplasia grade $2 / 3$ or cervical cancer, Int. J. Gynaecol. Obstet. 136 (2) (2017) 229-231, https://doi.org/10.1002/ ijgo.12030 Feb.

[15] W.W. Greenfield, S.L. Stratton, R.S. Myrick, R. Vaughn, L.M. Donnalley, H.N. Coleman, et al., A phase I dose-escalation clinical trial of a peptide-based human papillomavirus therapeutic vaccine with Candida skin test reagent as a novel vaccine adjuvant for treating women with biopsy-proven cervical intraepithelial neoplasia $2 / 3$, Oncoimmunology 27 (4(10)) (2015 May) e1031439 (no doi)

[16] D.M. Harper, L.R. DeMars, HPV vaccines - a review of the first decade, Gynecol. Oncol. 22 (Apr) (2017)https://doi.org/10.1016/j.ygyno.2017.04.004 pii: S00908258(17)30774-6.

[17] M. Kyrgiou, A. Mitra, M. Arbyn, S.M. Stasinou, P. Martin-Hirsch, P. Bennett, E. Paraskevaidis, Fertility and early pregnancy outcomes after treatment for cervical intraepithelial neoplasia: systematic review and meta-analysis, BMJ 349 (2014) g6192, https://doi.org/10.1136/bmj.g6192 Oct 28.

[18] M. Kyrgiou, A. Athanasiou, M. Paraskevaidi, A. Mitra, I. Kalliala, P. Martin-Hirsch, M. Arbyn, P. Bennett, E. Paraskevaidis, Adverse obstetric outcomes after local treatment for cervical preinvasive and early invasive disease according to cone depth: systematic review and meta-analysis, BMJ 28 (354) (2016 Jul) i3633, https://doi.org/10. 1136/bmj.i3633.

[19] M. Kyrgiou, A. Athanasiou, I.E.J. Kalliala, M. Paraskevaidi, A. Mitra, P.P. Martin-Hirsch, M. Arbyn, P. Bennett, E. Paraskevaidis, Obstetric outcomes after conservative treatment for cervical intraepithelial lesions and early invasive disease, Cochrane Database Syst. Rev. 2 (11) (2017 Nov) CD012847, https://doi.org/10.1002/14651858. CD012847.

[20] J.E. Palmer, S. Ravenscroft, K. Ellis, J. Crossley, N. Dudding, J.H. Smith, et al., Does LLETZ excision margin status predict residual disease in women who have undergone post-treatment cervical cytology and high-risk human papillomavirus testing? Cytopathology (2015 Sep 29)https://doi.org/10.1111/cyt.12260.

[21] L.D. Roman, S. Wilczynski, L.I. Muderspach, A.F. Burnett, A. O'Meara, J.A. Brinkman, W.M. Kast, G. Facio, J.C. Felix, M. Aldana, Weber JS. A phase II study of Hsp-7 (SGN-00101) in women with high-grade cervical intraepithelial neoplasia, Gynecol. Oncol. 106 (3) (2007 Sep) 558-566 , Epub 2007 Jul 12 https://doi.org/10.1016/j. ygyno.2007.05.038

[22] N. Santesso, R.A. Mustafa, W. Wiercioch, R. Kehar, S. Gandhi, Y. Chen, et al., Systematic reviews and meta-analyses of benefits and harms of cryotherapy, LEEP, and cold knife conization to treat cervical intraepithelial neoplasia, Int. J. Gynaecol. Obstet. 132 (3) (2016 Mar) 266-271, https://doi.org/10.1016/j.ijgo.2015.07.024.

[23] SAS Institute, Cary NC, USA version 9.4 (no doi)

[24] M. Schiffman, A.C. Rodríguez, Heterogeneity in CIN3 diagnosis, Lancet Oncol. 9 (5) (2008) 404-406, https://doi.org/10.1016/S1470-2045(08)70110-4 May.

[25] M.H. Silverman, M.L. Hedley, K.U. Petry, J.S. Weber, Clinical trials in cervical intraepithelial neoplasia: balancing the need for efficacy data with patient safety, J. Low. Genit. Tract Dis. 6 (4) (2002) 206-211 Oct. (no doi).

[26] A. Söderlund-Strand, L. Kjellberg, J. Dillner, Human papillomavirus type-specific persistence and recurrence after treatment for cervical dysplasia, J. Med. Virol. 86 (4) (2014) 634-641, https://doi.org/10.1002/jmv.23806 Apr.

[27] The case for starting sex education in kindergarten, https://www.pbs.org/ newshour/health/spring-fever 2015

[28] Trimble CL, Morrow MP, Kraynyak KA, Shen X, Dallas M, Yan J et al. Safety, efficacy, and immunogenicity of VGX-3100, a therapeutic synthetic DNA vaccine targeting human papillomavirus 16 and $18 \mathrm{E} 6$ and E7 proteins for cervical intraepithelial neoplasia 2/3: a randomised, double-blind, placebo-controlled phase $2 \mathrm{~b}$ trial. Lancet. 2015 Sep 16. pii: S0140-6736(15)00239-1. doi:https://doi.org/10.1016/S01406736(15)00239-1

[29] USPSTF Cervical Cancer Screening, https://www.uspreventiveservicestaskforce.org/ Page/Document/UpdateSummaryFinal/cervical-cancer-screening2 2018. 